\title{
Human Enteric Vaccines
}

Shanta Dutta ${ }^{1}$, Priyanka Jain ${ }^{1}$ and Sujit K Bhattacharya ${ }^{2 *}$

${ }^{1}$ Division of Bacteriology, National Institute of Cholera and Enteric Diseases, Kolkata, India

${ }^{2}$ National Institute of Pathology, New-Delhi, India

*Corresponding author: Sujit K Bhattacharya, NASI Senior Scientist and Platinum Jubilee Fellow, National Academy of Sciences, India, Tel: 91-8697462003; E-mail: sujitkbhattacharya@yahoo.com

Received date: 06 Aug 2014; Accepted date: 22 Sep 2014; Published date: 27 Sep 2014

Copyright: @ 2014 Dutta S et al. This is an open-access article distributed under the terms of the Creative Commons Attribution License, which permits unrestricted use, distribution, and reproduction in any medium, provided the original author and source are credited.

\begin{abstract}
Worldwide, enteric infections are the second commonest cause of disease burden due to all infectious diseases. It is estimated that they are responsible for 1.3 million deaths per year, mostly in children below 5 years of age in the developing world. Enteric infections are caused by a gamut of bacterial, viral and parasitic agents. These include viruses (rotaviruses, enteric adenoviruses, astroviruses, human caliciviruses), bacterial agents (Vibrio cholerae, Shigella spp., enterotoxigenic Escherichia coli, Salmonella spp. including Salmonella Typhi) and parasites. While suitable effective licensed vaccines are available against some of the enteric infections, many such diseases do not have a vaccine against them. Understanding the current scenario of vaccine development against these diseases is of paramount importance. This article reviews the current scenario in vaccine research and development against some of the common human viral and bacterial enteric pathogens of public health importance. Vaccines against parasitic diseases are not discussed.
\end{abstract}

Keywords: Enteric vaccines; Oral vaccines; Parenteral vaccines; Cholera; Rotavirus

\section{Introduction}

Enteric infections are major public health problem, especially affecting children in the developing world with an estimated 1.3 million deaths worldwide in 2008, which account for $15 \%$ of total global child death [1]. Diarrheal diseases are global killers, making diarrhea the second leading cause of death in infants and young children. It kills 2,195 children every day being higher than AIDS, malaria and measles combined [2]. Outbreaks of cholera, shigellosis, rotavirus diarrhea and typhoid fever occur frequently in resource-poor countries resulting in high disease burden, mortality and slow economic growth. World Health Organization (WHO) has given highest priority to the development of new or improved vaccines against rotavirus, Shigella spp., enterotoxigenic Escherichia coli (ETEC), Vibrio cholerae O1 and Salmonella Typhi [3].

It is believed that for enteric vaccines to be effective, mucosal immunity requires boosting up. Ideally, mucosal protection is best achieved by administration of a vaccine through the mucosa and oral route has been found to be the best choice $[3,4]$. Use of live, attenuated bacteria as protective vaccine antigens via the mucosal routes is effective against microbial infections [5]. Transgenic plants or fruits offer a new strategy for the delivery of safe, oral subunit vaccines against ETEC and cholera, which are likely to be suitable for use in developing countries [6]. This mode of vaccine delivery is yet to be fully established and the safety issues of such vaccines need to be addressed. This review focuses on licensed enteric vaccines (Table 1) as well as those that are under development in research mode (Table 2).

\begin{tabular}{|c|c|c|c|c|c|c|}
\hline Vaccines against & $\begin{array}{l}\text { Routes of } \\
\text { immunization }\end{array}$ & Active component (s) & Doses & $\begin{array}{l}\text { Names of Licensed } \\
\text { products } \\
\text { (manufacturers) }\end{array}$ & $\begin{array}{c}\text { Target population (age } \\
\text { of vaccinees) }\end{array}$ & References \\
\hline \multicolumn{7}{|l|}{ Cholera } \\
\hline $\begin{array}{l}\text { Killed whole-cell/ } \\
\text { recombinant cholera toxin } \\
\text { B-subunit vaccine (WC/ } \\
\text { rBS) }\end{array}$ & Oral & $\begin{array}{l}\text { Mixture of } 1011 \text { heat- } \\
\text { killed or formalin-killed. } \\
\text { CholeraeO1 of classical } \\
\text { and EI Tor biotypes and } \\
\text { Inaba and Ogawa } \\
\text { serotypes }+1 \text { mg CT B } \\
\text { subunit }\end{array}$ & 2 & Dukoral $^{\mathrm{TM}}$ (Crucell/SBL). & Children, adult & {$[10,11]$} \\
\hline $\begin{array}{lc}\text { CVD 103- } & \mathrm{HgR} \\
\text { recombinant } & \text { live } \\
\text { attenuated vaccine } & \end{array}$ & Oral & 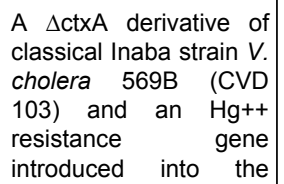 & 1 & $\begin{array}{l}\text { Berna, Swiss Serum and } \\
\text { Vaccine Institute as } \\
\text { Orachol (Europe), or } \\
\text { Mutacol }(\text { North America) }\end{array}$ & Children, adult & [13] \\
\hline
\end{tabular}


Page 2 of 9

\begin{tabular}{|c|c|c|c|c|c|c|}
\hline & & $\begin{array}{l}\text { Hemolysin A locus of } \\
\text { the chromosome. 108- } \\
109 \text { cfu }\end{array}$ & & & & \\
\hline $\begin{array}{l}\text { Killed whole cell (WC) } \\
\text { bivalent vaccine }\end{array}$ & Oral & 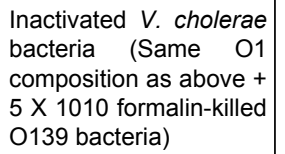 & 2 & $\begin{array}{l}\text { Shancol (in India) mORC- } \\
\text { Vax (in Vietnam) }\end{array}$ & Children, adult & [15] \\
\hline \multicolumn{7}{|l|}{ Typhoid } \\
\hline Live attenuated Ty21a & Oral & $\begin{array}{l}\mathrm{Vi} \text { negative mutant } \\
\text { strain of } S \text {. Typhi }\end{array}$ & 3 & Vivotif (Berna Biotech) & Children $>2 \mathrm{yr}$, adults & {$[22,23]$} \\
\hline Vi polysaccharide & Parenteral & $\begin{array}{l}\text { Purified } \mathrm{Vi} \text { capsular } \\
\text { polysaccharide }(\mathrm{CPS})\end{array}$ & 1 & $\begin{array}{lr}\text { Typhim Vi } & \text { (Sanofi } \\
\text { Pasteur)Typherix } \quad \text { (GSK) } \\
\text { TypBar (Bharat } \\
\text { Shotech); } \\
\text { Shantyph } \\
\text { (Shantha Biotech); Typho- } \\
\text { Vi (BioMed) }\end{array}$ & Children $>2 \mathrm{yr}$, adults & {$[24,25]$} \\
\hline $\begin{array}{l}\text { Conjugate vaccine } \\
\text { (Vi-TT) }\end{array}$ & Parenteral & $\begin{array}{l}\mathrm{Vi} \text { antigen is coupled to } \\
\text { tetanus toxoid protein }\end{array}$ & 2 & Peda-typhTM, (BioMed) & Children $<2 \mathrm{yr}$ & \\
\hline $\begin{array}{l}\text { Multivalent combination } \\
\text { vaccines }\end{array}$ & Parenteral & 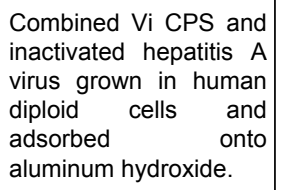 & 2 & $\begin{array}{lr}\text { HepatyrixTM, } & \text { (GSK); } \\
\text { ViatimTM, } & \text { (Aventis } \\
\text { Pasteur) } & \end{array}$ & $\begin{array}{l}\text { adults } \\
\text { adolescents }>15 \mathrm{yrs}\end{array}$ & {$[36]$} \\
\hline \multicolumn{7}{|l|}{ Rotavirus diarrhea } \\
\hline $\begin{array}{l}\text { Pentavalent human-bovine } \\
\text { reassortant WC3 vaccine }\end{array}$ & Oral & $\begin{array}{lr}\text { Bovine } & \text { WC } \\
\text { reassortant } & \text { viruses } \\
\text { carrying } & G 1, \quad G 2, \quad G 3 \\
\text { and } G 4 \text { of } P(8) & R N A \\
\text { segment } & \text { of } \\
\text { rotavirus }\end{array}$ & 3 & $\begin{array}{l}\text { RotaTeq }^{\text {TM }} \\
\text { Vaccines, USA) }\end{array}$ & Young infants & [50] \\
\hline $\begin{array}{l}\text { Monovalent } \quad \text { RIX-4414 } \\
\text { human rotavirus strain }\end{array}$ & Oral & $\begin{array}{l}\text { A } G 1 \quad P \text { [8] rotavirus } \\
\text { isolated from a human } \\
\text { infant that evoked } \\
\text { neutralizing antibodies } \\
\text { to rotaviruses of } G \\
\text { types } 1-4 .\end{array}$ & 2 & $\begin{array}{l}\text { Rotarix } \\
\text { Biologicals) }\end{array}$ & Young infants & [53] \\
\hline
\end{tabular}

Table 1: Licensed vaccines against common enteric diseases of public health importance (adapted from reference 3 ). ${ }^{*}$ Manufacturing was discontinued after 2004.

\section{Cholera}

Cholera is an acute watery diarrheal disease caused by Vibrio cholerae ( $V$. cholerae). The emergence of a new serogroup of $V$. cholerae O139 during early 1990s showed no cross-protection with serogroup O1, but remained confined to Bangladesh, India and other Asian countries [7]. Some cases were reported from developed countries, mostly among travelers [8]. The global burden of cholera is huge, particularly in developing countries. Every year an estimated 2.8 million cases of cholera and about 91,000 deaths occur in endemic countries [9].

A whole-cell injectable cholera vaccine was developed by Haffkine in 1894 in India and widely used throughout the world. This vaccine provided $48 \%$ protection for $3-5$ months only. The vaccine was highly reactogenic and required 2 doses for development of protective immunity. In view of this, the vaccine was not any further recommended and was withdrawn.
Two types of oral cholera vaccines (OCV) are available (Table 1). Both the vaccines have been shown to be safe, immunogenic and efficacious. One of them is an inactivated vaccine and the other one is a live attenuated vaccine. These two OCVs have been licensed in a few countries and are mainly used for travelers' from industrialized countries to cholera endemic areas [3]. The only inactivated oral vaccine that is currently recommended by WHO (DukoralTM, licensed by SBL Vaccine, Sweden) consists of heat- or formalin-killed whole-cell $V$. cholerae O1, representing both serotypes (Inaba and Ogawa) and both biotypes (classical and $\mathrm{El} \mathrm{Tor),} \mathrm{and} \mathrm{supplemented}$ with purified recombinant cholera toxin B-subunit (CTB) [3]. The whole cell/recombinant $\mathrm{B}$ subunit $(\mathrm{WC} / \mathrm{rBS}$ ) oral vaccine, which is given with buffer to neutralize stomach acidity, conferred $80 \%-90 \%$ protection during 6 months in all age groups in Bangladesh and Peru $[10,11]$. This was also used for mass vaccination among risk population to protect from emergence of potential outbreaks [12]. The second type of oral cholera vaccine consists of a live attenuated 
Page 3 of 9

genetically modified $V$. cholerae O1 Inaba strain (CVD103-HgR), which has been constructed so as to produce CTB but not the A subunit of CT (Cholera Toxin) [3]. Efficacy trial of a single dose of live oral cholera vaccine in North Jakarta, Indonesia showed only $15-20 \%$ protection at the end of third year of surveillance [13]. The vaccine has been licensed in several industrialized countries. Since, these are genetically modified bacteria, specific regulatory issues regarding their safety for humans and environmental use need to be elucidated [14].

A bivalent $\mathrm{O} 1$ and $\mathrm{O} 139$ killed whole-cell, oral vaccine without CTB was recently developed in Vietnam (Table 1). It was found to be safe and immunogenic in both adults and children, generating $90 \%$ anti$\mathrm{O} 1$ and $68 \%$ anti-O139 vibriocidal responses after administration of a two-dose regimen [15]. In a collaborative initiative, International Vaccine Institute (IVI), South Korea and Kolkata's National Institute of Cholera and enteric Diseases (NICED) conducted a Phase III, double-blind, placebo controlled, randomized clinical trial in Kolkata. This bivalent (O1 and O139) vaccine is currently the only potential vaccine against cholera caused by $\mathrm{O} 139$ serogroup and licensed for marketing following the documentation of $66 \%$ protection for two years post-vaccination and $65 \%$ cumulative protection at the end of 5 years in all age groups [16,17]. Recent findings showed that in addition to their direct vaccine-specific protection, OCVs also provide substantial indirect 'herd' protection to unvaccinated persons in the community due to minimization of the transmission of V. cholerae to unvaccinated people. The overall protection may approach $80 \%$ in settings with high coverage [18].

Among new generation unlicensed cholera vaccine, Peru 15 recombinant live oral vaccine was shown to be safe and immunogenic in Bangladeshi children [19].

\section{Typhoid Fever}

Typhoid fever is caused by Salmonella enterica serovar Typhi (S. Typhi). The case fatality rate has been reported to be as high as $10 \%-$ $20 \%$ in the absence of appropriate antibiotic treatment. However, due to the global emergence of strains resistant to commonly used drugs (chloramphenicol, ampicillin and co-trimoxazole) as well as fluoroquinolones, a tremendous therapeutic problem was encountered which indicated the need for a suitable vaccine effective against typhoid [20]. Typhoid fever remains a major cause of morbidity with an estimated global incidence of 22 million cases and 200,000 deaths per year [20]. In a recent multi-centric study in 5 Asian countries (China, India, Indonesia, Pakistan and Vietnam), it was estimated that the incidence of typhoid ranged from 15.3 per 100,000 persons/year in China to 451.7 per 100,000 persons/year in Pakistan. Population-based studies have demonstrated a wide variation in the incidence of typhoid fever both globally and within the same country [21].

First heat-killed, phenol preserved whole-cell $S$. typhi was used as parenteral vaccine in 1896 in Germany and England, but it lost popularity due to high reactogenicity [22]. Two other typhoid vaccines that are commercially available are the attenuated Ty21a live oral typhoid vaccine and the purified Vi polysaccharide (PS) parenteral typhoid vaccine [3].

The attenuated Ty21a live oral typhoid vaccine (Table 1) was tested in Phase III trials, initially in Egypt and then in Santiago, Chile, Indonesia and other countries. Randomized, controlled field trials involving children were conducted in these countries on the recommendations of the WHO and the Pan American Health Organization (PAHO). The vaccine elicited both anti-Salmonella antibodies and strong cell-mediated immune response. Three doses of the enteric-coated vaccine provided $67 \%$ protection over 3 years, and $62 \%$ protection over 7 years [23]. The field studies confirmed the efficacy and tolerability of Ty21a, and provided evidence of indirect protection (herd immunity).The vaccine is now licensed in 56 countries in Asia, Africa, Europe and the Americas [22,23].

The subunit Vi vaccine (Table 1) contains purified PS and elicits serum anti- $\mathrm{Vi}$ antibody response and is protective in $85 \%-95 \%$ of adults and children above 2 years of age after a single parenteral injection. S. typhi is highly sensitive to both complement-assisted killing and opsonophagocytotic effects via Vi-specific antibodies. This vaccine has been found to have $72 \%-77 \%$ efficacy in trials in Nepal and South Africa and is licensed in more than 92 countries globally $[24,25]$.

A locally produced Vi vaccine in Shanghai, China, demonstrated a $69 \%$ protective efficacy in a randomized double-blind, placebocontrolled trial amongst 5-19 years old children [26,27]. Single-dose mass vaccination campaigns targeting school children were carried out in Vietnam and Indonesia and were also conducted in China in both adults and children [28-30]. The impact of drug resistance may improve the cost effectiveness of mass vaccination programs in typhoid endemic countries [31]. Herd immunity was noted in a recent cluster-randomized effectiveness trial of Vi PS vaccine in Kolkata, India: a $44 \%$ reduction in typhoid among unvaccinated subjects was found that significantly contributed to the $61 \%$ overall vaccine protection [32].

The lack of immunogenicity of purified Vi PS in younger children has prompted the development of a conjugate $\mathrm{Vi}$ vaccine using Pseudomonas aeruginosa exotoxin A (Vi-rEPA) [33]. Persistent efficacy of $\mathrm{Vi}$ conjugate vaccine against typhoid fever in young children was observed following 3 years post vaccination in Vietnam and Cambodia [34]. Other carrier proteins like Tetanus toxoid, Corynebacterium diptheriae toxin were also used for conjugation [35]. Two multivalent combination vaccines (combination of Vi PS of $S$. typhi and inactivated Hepatitis A virus) marketed under the names Hepatyrix ${ }^{\mathrm{mm}}$ and Viatim ${ }^{\mathrm{m}}$ are available (Table 1). A prospective, randomized, observer-blind comparative study in healthy adults showed that both vaccines were well tolerated and induced high levels of protective antibodies [36].

New attenuated $S$. typhi strains that could be used as live oral vaccines are currently at an advanced clinical stage of development: Ty800, live attenuated oral single-dose vaccine, a phoP/phoQ deletion mutant of Ty2 has been shown to induce vigorous serum anti $\mathrm{O}$ antibody responses in Phase I trials [37]. The CVD908-htrA live attenuated oral vaccine, an $\operatorname{aroC} / \operatorname{aroD} / \mathrm{htrA}$ deletion mutant was tested in Phase II trials [35]. Attenuated S. typhi strain M01ZH09 oral vaccine developed by Emergent Biosolutions tested in Phase II trial induced serum and secretory IgA specific for surface antigens other than Vi (e.g., O and H) [38].

\section{Rotavirus Diarrhea}

Rotaviruses are the leading causes (25-55\%) of acute severe dehydrating diarrhea in infants and young children in both industrialized and developing countries and account for about $40 \%$ of hospitalizations in children under 5 years of age. Almost all children suffer from rotavirus infection/diarrhea within first 2-3 years of their lives. Outbreaks in day-care centers and hospitals are common and can spread rapidly [39]. 
Page 4 of 9

Rotavirus causes approximately 400,000 deaths each year, mostly in children below 2 years of age $[40,41]$. Up to $85 \%$ of these deaths occur in "low-income" countries. Rotaviruses were detected in $56 \%$ of stool specimens from hospitalized children with diarrhea in Vietnam, $41 \%$ in China, 56\% in Myanmar and 29\% in Hong Kong [42].

Rotaviruses are $70 \mathrm{~nm}$ icosahedral viruses that belong to the family Reoviridae. The virus is composed of three protein shells consisting of an outer and an inner capsids and an internal core with the 11 segments of the double-stranded RNA genome. Two structural outer capsid proteins, VP7 (G protein) and VP4 (P protein) define the G and $\mathrm{P}$ serotypes/genotypes of the virus, respectively. These are the major antigens involved in virus neutralization. Human rotaviruses bearing VP7 G serotypes G1-G4 and G9 and VP4 P genotypes P[4], P[6] and $\mathrm{P}[8]$ are predominant worldwide $[43,44]$. $\mathrm{P}[8] \mathrm{G} 1$ is the globally predominant strain, accounting for over $70 \%$ of rotavirus infections in North America, Europe and Australia, whereas about 30\% of the rotavirus infections in South America and Asia, and 23\% of those in Africa. Other frequently isolated strains are P [8]G3, P[4]G2, and P[8]G4 [45]. G9 strains emerged during late 1990s and became the predominant strains in some parts of Asia and Africa. Similarly, the distribution of the VP4 $\mathrm{P}[6]$ antigen is also different according to regions: $\mathrm{P}[6]$ strains constitute over $50 \%$ of the circulating strains in Africa, whereas P[8] strain is common in the rest of the world [46]. When mixed infections with distinct rotavirus strains occur, the gene segments may reassort independently, producing progeny "reassortants", which are important for viral diversity. An effective rotavirus vaccine should take into account such variations of prevalent strains [45-47].

The first rotavirus vaccine tested in humans was the live bovine strain RIT4237 (P[1]G6). Efficacy trials with this vaccine and other animal rotavirus strain derived vaccines did not show encouraging results leading to the discontinuation of these vaccines. In view of the inconsistency of the results, efforts were made to either use naturally attenuated human rotavirus strains or to develop reassortant rotavirus strains bearing a human rotavirus gene for the VP7 protein and other genes from a simian or a bovine rotavirus strain $[48,49]$.

The first live oral reassortant vaccine was developed by the National Institutes of Health (NIH, Bethesda) as a tetravalent mixture of the P[3]G3 rhesus RRV strain and human rotavirus strains of G types 1, 2, and 4 , respectively forming three independent rhesus-human reassortants [48]. The vaccine (RotaShield ${ }^{\mathrm{TM}}$ ) was introduced in 1998 by Wyeih-Lederle. But there was a major setback in 1999 leading to the withdrawal of RotaShield ${ }^{\mathrm{TM}}$ in less than a year after its introduction due to the reported intussusceptions in those who received the vaccines [49]. Subsequently, new live oral rotavirus vaccines have been developed [3].

More recently, a pentavalent human-bovine (WC3) reassortants (Gl, G2, G3, G4 with P[8] and G6 with P[7]) live-attenuated, 3-dose oral vaccine, has been developed (Table 1). The vaccine was administered at 6-12 weeks of age at 1-2 months intervals. This vaccine (RotaTeq ${ }^{\mathrm{m}}$ ) was tested in a Phase III trial in several countries including the USA and Finland on more than 70,000 children and carefully monitored for risks of intussusception. The vaccine was $74 \%$ efficacious in preventing any rotavirus disease and provided $98 \%$ protection in case of severe rotavirus diseases. In developing countries like Bangladesh and Vietnam, pentavalent rotavirus vaccines prevented severe rotavirus diarrhea by more than 50 percent during the first year of life, when children are at greatest risk for having rotavirus diarrhea [50]. Merck is marketing the licensed vaccine RotaTeq $^{\mathrm{TM}}$ globally [3].

Another multivalent bovine-human reassortant vaccine has been independently developed by the National Institute of Allergy and Infectious Diseases (NIAID, NIH, Bethesda). Analysis of Phase II data revealed a good immune response and no adverse interference with concomitantly administered childhood vaccines were noted [51]. Two naturally occurring human-bovine, neonate derived, reassortant strains (116E and 1321) are under development in India in partnership with Centers for Disease Control and Prevention (CDC), USA and the Children's Vaccine Programme funded by the Program for Appropriate Technology in Health (PATH). These strains have $\mathrm{P}[10] \mathrm{G} 9$ and $\mathrm{P}[11] \mathrm{G} 10$ antigens, respectively [52].

A monovalent (P[8]G1) live-attenuated, 2-dose oral vaccine has been developed from a human rotavirus strain RIX-4414 (Table 1). The vaccine (Rotatrix ${ }^{\prime \prime \prime}$ ) has been tested in Latin American and European countries in a phase III trial on more than 63,000 children. The vaccine was $85-100 \%$ efficacious in preventing severe rotavirus disease. No increased attributable risk of intussusception was reported. The vaccine has been licensed in several countries in Latin America, Asia, Africa and Europe [53]. Phase II clinical trials were conducted in developing countries like Bangladesh, Vietnam and Philippines to investigate the safety and immunogenicity of the vaccine when given concomitantly with the oral polio vaccine (OPV). The Rotatrix vaccine was found to be immunogenic when co-administered with OPV and did not interfere with OPV sero-protection rates in the infants [54,55].

Based on the clinical trial data from Asia and Africa, in 2009, the WHO's Strategic Advisory Group of Experts (SAGE) recommended that all countries should include rotavirus vaccines in their national immunization programs. Significant declines in hospitalization and deaths due to rotavirus and all-cause diarrhea have been observed in many of the countries that have introduced rotavirus vaccines [56,57]. Unvaccinated children and adults were found to be protected due to "herd immunity" [58]. The Global Alliance for Vaccines and Immunizations (GAVI) is sponsoring a new Public-Private organization, the Rotavirus Vaccine Programme at PATH, whose role is to accelerate the development and introduction of rotavirus vaccines in developing countries. Post marketing surveillance is required to measure the extent of cross-protection of the existing vaccine against different rotavirus serotypes, including serotype G9, which is becoming increasingly important across Asia and Africa.

\section{Shigellosis}

Shigellosis remains an important cause of morbidity and mortality globally, particularly among children less than 5 years of age in developing countries. In 1999, it was estimated that Shigellae caused approximately 113 million episodes and 0.6 million deaths annually. In addition, about 500,000 cases of shigellosis are reported each year among travelers and military personnel from industrialized countries [59].

Since Shigellae invade and destroys intestinal mucosa, antimicrobial therapy is the cornerstone of treatment for shigellosis, but the option is gradually narrowed down due to widespread occurrences of multidrug resistant strains in Asia where even resistance to ciprofloxacin has been observed [60]. Resistance has increased also to the second line choices like pivmecillinam and azithromycin (30-50\%) and to the third generation cephalosporin [60,61]. Increasing occurrences of 
outbreaks and spread of multidrug resistant Shigellae dysenteriae type1 strains is a matter of great concern [60]. It is imperative that there is an urgent need for a safe and effective Shigella vaccine to control the disease, but unfortunately currently no such vaccine is available.

There are four serogroups of Shigellae: $S$. sonnei, $S$. flexneri, $S$. dysenteriae, and $S$. boydii. These serogroups are subdivided into serotypes on the basis of the O-polysaccharide antigen of their lipopolysaccharide (LPS). $S$. sonnei is the predominant serogroup in industrialized countries, where it accounts for $77 \%$ of cases compared to $15 \%$ in developing countries. It was also the commonly obtained isolate in Thailand in recent years, a phenomenon possibly linked to the level of economic development of the country and tourists from developed regions. $S$. flexneri is endemic in developing countries and is the most frequently $(60 \%)$ isolated species worldwide. The predominant serotype of $S$. flexneri is serotype 2a, followed by lb, 3a, $4 \mathrm{a}$ and 6 , although recent studies from Asian countries showed wide variations in the prevalence of these serotypes. $S$. boydii is the relatively uncommon serotype. $S$. dysenteriae serotype 1 is notorious for being multidrug resistant and has caused large scale severe epidemics of dysentery [59]

Antibody directed to the $\mathrm{O}$ somatic antigen of Shigellae is protective and is type specific. In view of the large number of Shigella serotypes, vaccine development against all serotypes is complex, although it is observed that a vaccine could give cross-reactive protection. Candidate shigellosis vaccines that are currently under development include both killed and live vaccines and are mostly targeted against $S$. flexneri $[3,62,63]$. Two approaches to develop Shigella vaccines have demonstrated reasonable protection in field trials. The first approach is the development of conjugate vaccines in which Shigella O-polysaccharides are linked to carrier proteins. The second approach is the development of live oral vaccines after attenuation of wild-type Shigellae spp. [3,64]. These vaccines are at preclinical stage (Table 2). This approach includes:

- Parenteral conjugate vaccines comprising of purified $S$. dysenteriae type 1 LPS conjugated to tetanus toxoid; $S$. flexneri 2a and $S$. sonnei LPS conjugated to recombinant Pseudomonas aeruginosa exotoxin A [65]. These vaccines were developed at the NIH, were safe and immunogenic in children greater than 4 years of age and afforded $74 \%$ protection when tested in field trials with Israeli military volunteers, except in pre-school children $[66,67]$.

- A nasally administered bivalent invasin complex vaccine (Invaplex) against $S$. flexneri 2 a and $S$. sonnei developed by Walter Reed Army Institute of Research (WRAIR), US is under evaluation [68].

- A nasally administered proteosome vaccine consisting of $S$. sonnei and $S$. flexneri 2a LPS linked to the outer membrane protein of group B Neisseria meningitides [69].

Definite progress has been made with candidate live oral Shigella vaccines (Table 2), but the problem remains with them that underattenuation causes excessive reactogenicity and over-attenuation leads to poor immunogenicity in human subjects. These approaches include:

- $\quad$ A live, attenuated $S$. sonnei WRSS1 was developed by WRAIR with a single deletion mutation of the virG gene as oral Shigella vaccine. The safety and immunogenicity of the vaccine was tested in Israeli volunteer in phase II trial and the vaccine was found to elicit a significant immune response [70].
- $\quad$ A live, attenuated $S$. flexneri 2a strain (SC602), carrying mutations in their icsA (virG), iuc, int and toxA (stxA) genes and a $S$. dysenteriae type 1 strain (SC599) carrying mutations in their icsA, ent, fep and stxA genes were developed at the Pasteur Institute, Paris [71-73]. SC602 was tested in adult volunteers in the USA and in both adults and children in Bangladesh, although the outcome was not so encouraging in Bangladesh study [71,72]. SC599 was well tolerated in their phase II trials. A single oral immunization of SC599 vaccine elicited a significantly higher circulating IgAantibody secretory cells and serum antibody, when compared to phase I trials [73].

- A series of strains were made auxotrophic for aromatic amino acids synthesis (amA) and guanine synthesis (guaBA) with progressive deletions of virulence genes virG, set (ShET-1) and sen (ShET-2) resulting in construction of CVD1203, CVD 1204, etc. culminating in strain CVD1208S, which was safe and immunogenic in phase I studies [74].

\section{Enterotoxigenic Escherichia coli}

Enterotoxigenic E. coli (ETEC) remains the major cause of infantile diarrheas in the developing world and of traveler's diarrheas in the industrialized countries among the travelers visiting the third world countries [75].

ETEC infections are characterized by profuse watery diarrhea, generally clinically indistinguishable from cholera, leading to dehydration and malnutrition in young children. ETEC causes approximately 280 million diarrhea based episodes and more than 400,000 deaths annually [76,77]. Active community and hospital surveillance in Bangladesh has shown that the prevalence of ETEC infections were $14-23 \%$ in children with diarrhea and $8 \%$ in asymptomatic children. ETEC are globally responsible for about $25 \%$ of persistent diarrheas and $26 \%$ of severe diarrheas requiring hospitalization [78].

ETEC attaches to specific receptors of the enterocytes in the small intestinal lumen by the hair-like fimbriae, which function as adhesins and define strain-specific antigenicity. More than 25 types of fimbrial antigens, called coli surface antigens (CSs) or colonization factor antigens (CFAs) have been described, with seven types (CFA/I and CS1 through CS6) occurring most frequently. Antibodies targeted to fimbriae are protective but showed serotype-specificity. Once attached to the intestinal epithelium, ETEC elaborates a heat-labile toxin (LT) and/or a heat-stable toxin (ST), which induces the watery diarrhea. Approximately one half of ETEC strains secrete only ST, 25\% secrete only LT, and the remaining $25 \%$ secrete both LT and ST. LT is highly homologous to cholera toxin (CT) comprising of an active A subunit surrounded by five B subunits for attachment. ST is a small peptide toxin of 18 or 19 amino acids. Since ST is not immunogenic, it is not a suitable candidate for vaccine $[3,78]$.

ETEC infections in children in developing countries confer immunity against subsequent infection as reflected by declining rates of ETEC diarrhea with increasing age and lower ratios of symptomatic to asymptomatic ETEC infections in adults. The protection against subsequent infections occurs if the infecting strains have similar toxin and/or colonization factor phenotypes to that of initial strains. Thus immunization against ETEC early in life is expected to confer effective protection. Travelers from industrialized country and military troops on deployment are important potential target population for vaccination against ETEC $[78,79]$. 
Page 6 of 9

The oral killed WC/rBS cholera vaccine (Dukoral' as stated earlier) was found to prevent $23 \%$ of all diarrhea episodes and $52 \%$ of episodes due to ETEC in tourists which did not last more than a few months
[80]. Several approaches have been pursued to develop specific ETEC vaccines (Table 2 ).

\begin{tabular}{|c|c|c|c|c|c|}
\hline Vaccine & Immunization route & $\begin{array}{ll}\text { No. } & \text { of } \\
\text { doses } & \end{array}$ & Developer & Status & References \\
\hline \multicolumn{6}{|l|}{ Shigellosis } \\
\hline Attenuated S. sonnei strain WRSS1 & Oral & 2 & $\begin{array}{l}\text { Walter Reed Army Institute of } \\
\text { Research }\end{array}$ & Phase II & [70] \\
\hline Attenuated S. flexneri2a strain CVD $1208 \mathrm{~S}$ & Oral & 2 & $\begin{array}{l}\text { Center for Vaccine Development, } \\
\text { University of Maryland }\end{array}$ & Phase I & [74] \\
\hline Attenuated S. flexneri2a strain SC602 & Oral & $1-2$ & Pasteur Institute & Phase II & [71] \\
\hline Attenuated S. dysenteriae 1 strain SC599 & Oral & 2 & Pasteur Institute & Phase II & [73] \\
\hline $\begin{array}{l}\text { Shigella glycoconjugates }(O \text { polysaccharide } \\
\text { covalently linked to carrier protein) }\end{array}$ & Intra-muscular & 2 & $\begin{array}{l}\text { National Institute of Health and } \\
\text { Human Development }\end{array}$ & Phase III & [65] \\
\hline Shigella invasion complex (Invaplex) & Nasal & 3 & $\begin{array}{l}\text { Walter Reed Army Institute of } \\
\text { Research }\end{array}$ & Phase I & [68] \\
\hline $\begin{array}{l}\text { Proteosomes (OMP of Group B meningitides) to } \\
\text { which S. sonnei or S. flexneri2a LPS is adsorbed }\end{array}$ & Nasal & 2 & ID Biomedical* & Phase I & [69] \\
\hline \multicolumn{6}{|l|}{ ETEC diarrhea } \\
\hline $\begin{array}{l}\text { B subunit-inactivated whole fimbriated ETEC } \\
\text { combination }\end{array}$ & Oral & 2 & University of Goteborg and SBL & Phase III & [82] \\
\hline $\begin{array}{l}\text { Attenuated fimbriated non-toxigenic } \\
\text { (derived from ETEC) }\end{array}$ & Oral & 2 & Cambridge Biostability Ltd. & Phase I & [88] \\
\hline $\begin{array}{l}\text { Attenuated Shigella strains expressing ETEC } \\
\text { fimbrial colonization factors and } B \text { subunit of } L T h^{* *}\end{array}$ & Oral & 2 & $\begin{array}{l}\text { Center for Vaccine Development, } \\
\text { University of Maryland }\end{array}$ & Phase I & [86] \\
\hline
\end{tabular}

Table 2: New generation unlicensed vaccines against Shigella and ETEC (adapted from ref. 3 ). ${ }^{*}$ Now GSK Biologicals. ${ }^{* *}$ LTh, LT from a human ETEC strain.

One of the most successful vaccine approach developed by the investigators at the University of Goteborg (Sweden) is based on recombinant CTB combined with 4 formalin-killed ETEC strains that collectively express the colonization factors of epidemiological importance in developing countries [78,81]. Phase II studies of 2-doses of this vaccine have been conducted in Bangladesh, Egypt, Israel, Nicaragua, the USA and Europe. This vaccine was safe and immunogenic by inducing mucosal antibody responses to CTB and to the CFA components of the vaccine. The vaccine was less than $20 \%$ effective against ETEC infections in the very young [82]. Several factors were involved for these observations. Studies in US travelers showed $60 \%-84 \%$ protection against severe incapacitating diarrhea [83]. CS6 protein antigens could induce systemic immune responses in the presence of an adjuvant such as LT [84]. ST is not immunogenic even if coupled to a protein carrier and was very reactogenic. Lastly, feeding volunteers with transgenic corn or potatoes expressing the LT B subunit resulted in significant serum and gut antibody responses [85]. At the Center for Vaccine Development (CVD), University of Maryland (USA), the vaccine approach being pursued is by using live attenuated Shigella vectors for expression of ETEC fimbrial and LT antigens. Such constructs protect against both Shigella and ETEC [86]. The same approach is being followed by Micro science using their spiVEC oral live attenuated typhoid vaccine as a vector for the delivery of ETEC antigens [87].
Two non-toxigenic ETEC strains have been attenuated by mutagenesis of the aroC and ompR genes or of the aroC, ompC and ompF genes, respectively, to be used as candidate live, oral attenuated vaccines. The mutagenized strains were found to be well tolerated and immunogenic when fed to human volunteers [88]. But none of these ETEC candidate vaccines were found to be protective in infants and young children in the endemic areas. Intense efforts need to be made to improve the immunogenicity of the candidate vaccines. The strategy is to include toxin antigen alone or together with overexpressing colonizing factors antigens $[89,90]$.

\section{Conclusion}

In recent years, there is an increased research interest for understanding the biology and development of enteric vaccines due to improved knowledge about the mucosal immune system together with the development of improved methodologies for measuring local immune responses, both humoral and cell-mediated immunity. Several new enteric vaccines are in different stages of clinical testing, including improved alternatives to existing vaccines. Oral route has been extensively studied for mucosal vaccination due to its many attractive features. But the tolerance is a crucial challenge in the development of effective oral vaccines. Other challenges, including antigen degradation by proteolytic enzymes, the low dose of antigen absorbed, a lack of potent mucosal adjuvants, and difficulty in 
directing antigens to $\mathrm{M}$ cells, are also responsible for the nonavailability of a potent oral vaccine. Two areas that could revolutionize enteric vaccine research are (i) the development of new well-tolerated mucosal adjuvants that could influence the innate immune system visà-vis enhance the adaptive immune response to oral vaccines and (ii) the use of lectins or other means to target vaccine antigens or use of delivery vehicles for direct delivery of the purified subunit antigens to intestinal $\mathrm{M}$ cells.

The ability of $M$ cells in Peyer's patches to take up diverse numbers of microorganisms to antigen-presenting cells (APCs) have made M cells an ideal target for delivery of vaccine to the mucosal immune system. Targeting specific receptors on the apical surface of $M$ cells may have the ability to specifically increase the uptake and presentation of antigens, consequently initiating higher immune response and inducing protection against infectious agents [91]. WHO prequalified safe and effective enteric vaccines are licensed and commercially available in several countries. Some countries have introduced them in their routine immunization programs. During implementation of an enteric vaccine in developing countries where the disease is endemic, it was observed that poor people living in the slum communities prefer to have safe water, improved sanitation, housing and not the vaccines. It is true that safe water supply and promotion of good sanitation practice are the permanent measures to prevent diseases, improve the health and quality of life of people in a country, but achieving this is a difficult proposition in resource poor countries in near future. It is imperative that researchers should not only contribute to the development of suitable vaccines, but, it is also their responsibility to sensitize the political leaders, bureaucrats, policymakers and the common people about the cost-effectiveness, overall benefits and their impact on economic growth by introduction of these vaccines in routine immunization programs of the countries, which would mitigate the suffering of poor people. Oral cholera vaccine is now ready to be introduced in endemic areas. The vaccine should be used before the cholera season so that, it will prevent the occurrence of outbreaks and minimize the number of cholera cases.

\section{References}

1. Black RE, Cousens S, Johnson HL, Lawn JE, Rudan I, et al. (2010) Global, regional, and national causes of child mortality in 2008: a systematic analysis. Lancet 375: 1969-1987.

2. http://www.cdc.gov/healthywater/global/diarrhea-burden.html.

3. Petri WA Jr, Miller M, Binder HJ, Levine MM, Dillingham R, et al. (2008) Enteric infections, diarrhea, and their impact on function and development. J Clin Invest 118: 1277-1290.

4. Holmgren J, Svennerholm AM (2012) Vaccines against mucosal infections. Curr Opin Immunol 24: 343-353.

5. Roland KL, Tinge SA, Killeen KP, Kochi SK (2005) Recent advances in the development of live, attenuated bacterial vectors. Curr Opin Mol Ther 7: 62-72.

6. Tacket CO (2004) Plant-derived vaccines against diarrhoeal diseases. Expert Opin Biol Ther 4: 719-728.

7. Ramamurthy T, Garg S, Sharma R, Bhattacharya SK, Nair GB, et al. (1993) Emergence of novel strain of Vibrio cholerae with epidemic potential in southern and eastern India. Lancet 341: 703-704.

8. Steinberg EB, Greene KD, Bopp CA, Cameron DN, Wells JG, et al. (2001) Cholera in the United States, 1995-2000: trends at the end of the twentieth century. J Infect Dis 184: 799-802.

9. Ali M, Lopez AL, You YA, Kim YE, Sah B, et al. (2012) The global burden of cholera. Bull World Health Organ 90: 209-218A.
10. Clemens JD, Sack DA, Harris JR, Van Loon F, Chakraborty J, et al. (1990) Field trial of oral cholera vaccines in Bangladesh: results from three-year follow-up. Lancet 335: 270-273.

11. Sanchez JL, Vasquez B, Begue RE, Meza R, Castellares G, et al. (1994) Protective efficacy of oral whole-cell/recombinant-B-subunit cholera vaccine in Peruvian military recruits. Lancet 344: 1273-1276.

12. Legros D, Paquet C, Perea W, Marty I, Mugisha NK, et al. (1999) Mass vaccination with a two-dose oral cholera vaccine in a refugee camp. Bull World Health Organ 77: 837-842.

13. Richie EE, Punjabi NH, Sidharta YY, Peetosutan KK, Sukandar MM, et al. (2000) Efficacy trial of single-dose live oral cholera vaccine CVD 103$\mathrm{HgR}$ in North Jakarta, Indonesia, a cholera-endemic area. Vaccine 18: 2399-2410.

14. Viret JF, Dietrich G, Favre D (2004) Biosafety aspects of the recombinant live oral Vibrio cholerae vaccine strain CVD 103-HgR. Vaccine 22: 2457-2469.

15. Trach DD, Cam PD, Ke NT, Rao MR, Dinh D, et al. (2002) Investigations into the safety and immunogenicity of a killed oral cholera vaccine developed in Viet Nam. Bull World Health Organ 80: 2-8.

16. Sur D, Lopez AL, Kanungo S, Paisley A, Manna B, et al. (2009) Efficacy and safety of a modified killed-whole-cell oral cholera vaccine in India: an interim analysis of a cluster-randomised, double-blind, placebocontrolled trial. Lancet 374: 1694-1702.

17. Sur D, Kanungo S, Sah B, Manna B, Ali M, et al. (2011) Efficacy of a lowcost, inactivated whole-cell oral cholera vaccine: results from 3 years of follow-up of a randomized, controlled trial. PLoS Negl Trop Dis 5: e1289.

18. Ali M, Emch M, von Seidlein L, Yunus M, Sack DA, et al. (2005) Herd immunity conferred by killed oral cholera vaccines in Bangladesh: a reanalysis. Lancet 366: 44-49.

19. Qadri F, Chowdhury MI, Faruque SM, Salam MA, Ahmed T, et al. (2007) Peru-15, a live attenuated oral cholera vaccine, is safe and immunogenic in Bangladeshi toddlers and infants. Vaccine 25: 231-238.

20. Crump JA, Luby SP, Mintz ED (2004) The global burden of typhoid fever. Bull World Health Organ 82: 346-353.

21. Ochiai RL, Acosta CJ, Danovaro-Holliday MC, Baiqing D, Bhattacharya SK, et al. (2008) A study of typhoid fever in five Asian countries: disease burden and implications for controls. Bull World Health Organ 86: 260-268.

22. Levine MM (2004) Typhoid fever vaccines: Vaccines. (4thedn), Saunders, Philadelphia.

23. Levine MM, Ferreccio C, Abrego P, Martin OS, Ortiz E, et al. (1999) Duration of efficacy of Ty21a, attenuated Salmonella typhi live oral vaccine. Vaccine 17 Suppl 2: S22-27.

24. Acharya IL, Lowe CU, Thapa R, Gurubacharya VL, Shrestha MB, et al. (1987) Prevention of typhoid fever in Nepal with the Vi capsular polysaccharide of Salmonella typhi. A preliminary report. N Engl J Med 317: 1101-1104.

25. http://whqlibdoc.who.int/hq/2003/WHO_V\&B_03.07.pdf

26. Yang HH, Wu CG, Xie GZ, Gu QW, Wang BR, et al. (2001) Efficacy trial of $\mathrm{Vi}$ polysaccharide vaccine against typhoid fever in south-western China. Bull World Health Organ 79: 625-631.

27. Acosta CJ, Hong-Hui Y, Ning W, Qion G, Qun D, et al. (2005) Efficacy of a locally produced, Chinese Vi polysaccharide typhoid fever vaccine during six years of follow-up. Vaccine 23: 5618-5623.

28. Yang J, Acosta CJ, Si GA, Zeng J, Li CY, et al. (2005) A mass vaccination campaign targeting adults and children to prevent typhoid fever in Hechi; Expanding the use of Vi polysaccharide vaccine in Southeast China: A cluster-randomized trial. BMC Public Health 5: 49.

29. Thiem VD, Danovaro-Holliday MC, Canh do G, Son ND, Hoa NT, et al. (2006) The feasibility of a school-based VI polysaccharide vaccine mass immunization campaign in Hue City, central Vietnam: streamlining a typhoid fever preventive strategy. Southeast Asian J Trop Med Public Health 37: 515-522.

30. Agtini MD, Ochiai RL, Soeharno R, Lee HJ, Sundoro J, et al. (2006) Introducing $\mathrm{Vi}$ polysaccharide typhoid fever vaccine to primary school 
Page 8 of 9

children in North Jakarta, Indonesia, via an existent school-based vaccination platform. Public Health 120: 1081-1087.

31. Levine MM (2006) Mass vaccination to control epidemic and endemic typhoid fever. Curr Top Microbiol Immunol 304: 231-246.

32. Sur D, Ochiai RL, Bhattacharya SK, Ganguly NK, Ali M, et al. (2009) A cluster-randomized effectiveness trial of Vi typhoid vaccine in India. $\mathrm{N}$ Engl J Med 361: 335-344.

33. Szu SC, Taylor DN, Trofa AC, Clements JD, Shiloach J, et al. (1994) Laboratory and preliminary clinical characterization of $\mathrm{Vi}$ capsular polysaccharide-protein conjugate vaccines. Infect Immun 62: 4440-4444.

34. Mai NL, Phan VB, Vo AH, Tran CT, Lin FY, et al. (2003) Persistent efficacy of $\mathrm{Vi}$ conjugate vaccine against typhoid fever in young children. N Engl J Med 349: 1390-1391.

35. Garmory HS, Brown KA, Titball RW (2002) Salmonella vaccines for use in humans: present and future perspectives. FEMS Microbiol Rev 26: 339-353.

36. Beeching NJ, Clarke PD, Kitchin NR, Pirmohamed J, Veitch K, et al. (2004) Comparison of two combined vaccines against typhoid fever and hepatitis A in healthy adults. Vaccine 23: 29-35.

37. Hohmann EL, Oletta CA, Killeen KP, Miller SI (1996) phoP/phoQdeleted Salmonella typhi (Ty800) is a safe and immunogenic single-dose typhoid fever vaccine in volunteers. J Infect Dis 173: 1408-1414.

38. Kirkpatrick BD, McKenzie R, O'Neill JP, Larsson CJ, Bourgeois AL, et al. (2006) Evaluation of Salmonella enterica serovar Typhi (Ty2 aroC-ssaV-) M01ZH09, with a defined mutation in the Salmonella pathogenicity island 2, as a live, oral typhoid vaccine in human volunteers. Vaccine 24: $116-123$.

39. Clark HF, Offit PA, Glass RI, Ward RL (2004) Rotavirus vaccines: Vaccines. (4thedn), Saunders, Philadelphia.

40. Tate JE, Burton AH, Boschi-Pinto C, Steele AD, Duque J, et al. (2012) 2008 estimate of worldwide rotavirus-associated mortality in children younger than 5 years before the introduction of universal rotavirus vaccination programmes: a systematic review and meta-analysis. Lancet Infect Dis 12: 136-141.

41. http://www.who.int/entity/immunization_monitoring/ burden/ ChildRota2008.xls.

42. Nguyen VM, Nguyen VT, Huynh PL, Dang DT, Nguyen TH, et al. (2001) The epidemiology and disease burden of rotavirus in Vietnam: sentinel surveillance at 6 hospitals. J Infect Dis 183: 1707-1712.

43. Hoshino Y, Kapikian AZ (2000) Rotavirus serotypes: classification and importance in epidemiology, immunity, and vaccine development. J Health Popul Nutr 18: 5-14.

44. Koshimura Y, Nakagomi T, Nakagomi O (2000) The relative frequencies of $\mathrm{G}$ serotypes of rotaviruses recovered from hospitalized children with diarrhea: A 10-year survey (1987-1996) in Japan with a review of globally collected data. Microbiol Immunol 44: 499-510.

45. Santos N, Hoshino Y (2005) Global distribution of rotavirus serotypes/ genotypes and its implication for the development and implementation of an effective rotavirus vaccine. Rev Med Virol 15: 29-56.

46. Steele AD, Ivanoff B (2003) Rotavirus strains circulating in Africa during 1996-1999: emergence of G9 strains and P[6] strains. Vaccine 21: 361-367.

47. Franco MA, Greenberg HB (2001) Challenges for rotavirus vaccines. Virology 281: 153-155.

48. Midthun K, Kapikian AZ (1996) Rotavirus vaccines: an overview. Clin Microbiol Rev 9: 423-434.

49. Jacobson RM (1999) The current status of the rotavirus vaccine. Vaccine 17: 1690-1699.

50. Zaman K, Dang DA, Victor JC, Shin S, Yunus M, et al. (2010) Efficacy of pentavalent rotavirus vaccine against severe rotavirus gastroenteritis in infants in developing countries in Asia: a randomised, double-blind, placebo-controlled trial. Lancet 376: 615-623.

51. Clements-Mann ML, Dudas R, Hoshino Y, Nehring P, Sperber E, et al. (2001) Safety and immunogenicity of live attenuated quadrivalent human-bovine (UK) reassortant rotavirus vaccine administered with childhood vaccines to infants. Vaccine 19: 4676-4684.

52. Glass RI, Bhan MK, Ray P, Bahl R, Parashar UD, et al. (2005) Development of candidate rotavirus vaccines derived from neonatal strains in India. J Infect Dis 192 Suppl 1: S30-35.

53. Jones T (2001) Rotavirus vaccine AVANT/GlaxoSmithKline. Curr Opin Investig Drugs 2: 893-895.

54. Zaman K, Sack DA, Yunus M, Arifeen SE, Podder G, et al. (2009) Successful co-administration of a human rotavirus and oral poliovirus vaccines in Bangladeshi infants in a 2-dose schedule at 12 and 16 weeks of age. Vaccine 27: 1333-1339.

55. Anh DD, Carlos CC, Thiem DV, Hutagalung Y, Gatchalian S, et al. (2011) Immunogenicity, reactogenicity and safety of the human rotavirus vaccine RIX4414 (Rotarix ${ }^{\mathrm{m}}$ ) oral suspension (liquid formulation) when co-administered with expanded program on immunization (EPI) vaccines in Vietnam and the Philippines in 2006-2007. Vaccine 29: 2029-2036.

56. [No authors listed] (2009) Meeting of the immunization Strategic Advisory Group of Experts, April 2009--conclusions and recommendations. Wkly Epidemiol Rec 84: 220-236.

57. Patel MM, Steele D, Gentsch JR, Wecker J, Glass RI, et al. (2011) Realworld impact of rotavirus vaccination. Pediatr Infect Dis J 30: S1-5.

58. Lopman BA, Curns AT, Yen C, Parashar UD (2011) Infant rotavirus vaccination may provide indirect protection to older children and adults in the United States. J Infect Dis 204: 980-986.

59. Kotloff KL, Winickoff JP, Ivanoff B, Clemens JD, Swerdlow DL, et al (1999) Global burden of Shigella infections: implications for vaccine development and implementation of control strategies. Bull World Health Organ 77: 651-666.

60. Zhang W, Luo Y, Li J, Lin L, Ma Y, et al. (2011) Wide dissemination of multidrug-resistant Shigella isolates in China. J Antimicrob Chemother 66: 2527-2535.

61. Vinh H, Baker S, Campbell J, Hoang NV, Loan HT, et al. (2009) Rapid emergence of third generation cephalosporin resistant Shigella spp. in Southern Vietnam. J Med Microbiol 58: 281-283.

62. Nataro JP, Barry EM (2004) Diarrheal Disease Vaccines: Vaccines. (4thedn), Saunders, Philadelphia.

63. Jennison AV, Verma NK (2004) Shigella flexneri infection: pathogenesis and vaccine development. FEMS Microbiol Rev 28: 43-58.

64. Barry EM, Pasetti MF, Sztein MB, Fasano A, Kotloff KL, et al. (2013) Progress and pitfalls in Shigella vaccine research. Nat Rev Gastroenterol Hepatol 10: 245-255.

65. Cohen D, Ashkenazi S, Green MS, Gdalevich M, Robin G, et al. (1997) Double-blind vaccine-controlled randomised efficacy trial of an investigational Shigella sonnei conjugate vaccine in young adults. Lancet 349: 155-159.

66. Passwell JH, Harlev E, Ashkenazi S, Chu C, Miron D, et al. (2001) Safety and immunogenicity of improved Shigella O-specific polysaccharideprotein conjugate vaccines in adults in Israel. Infect Immun 69: 1351-1357.

67. Passwell JH, Ashkenzi S, Banet-Levi Y, Ramon-Saraf R, Farzam N, et al. (2010) Age-related efficacy of Shigella O-specific polysaccharide conjugates in 1-4-year-old Israeli children. Vaccine 28: 2231-2235.

68. Oaks EV, Turbyfill KR (2006) Development and evaluation of a Shigella flexneri $2 \mathrm{a}$ and S. sonnei bivalent invasin complex (Invaplex) vaccine. Vaccine 24: 2290-2301.

69. Fries LF, Montemarano AD, Mallett CP, Taylor DN, Hale TL, et al. (2001) Safety and immunogenicity of a proteosome-Shigella flexneri 2a lipopolysaccharide vaccine administered intranasally to healthy adults. Infect Immun 69: 4545-4553.

70. Orr N, Katz DE, Atsmon J, Radu P, Yavzori M, et al. (2005) Communitybased safety, immunogenicity, and transmissibility study of the Shigella sonnei WRSS1 vaccine in Israeli volunteers. Infect Immun 73: 8027-8032.

71. Katz DE, Coster TS, Wolf MK, Trespalacios FC, Cohen D, et al. (2004) Two studies evaluating the safety and immunogenicity of a live, 
attenuated Shigella flexneri 2a vaccine (SC602) and excretion of vaccine organisms in North American volunteers. Infect Immun 72: 923-930.

72. Rahman KM, Arifeen SE, Zaman K, Rahman M, Raqib R, et al. (2011) Safety, dose, immunogenicity, and transmissibility of an oral live attenuated Shigella flexneri 2a vaccine candidate (SC602) among healthy adults and school children in Matlab, Bangladesh. Vaccine 29: 1347-1354.

73. Launay O, Sadorge C, Jolly N, Poirier B, Béchet S, et al. (2009) Safety and immunogenicity of SC599, an oral live attenuated Shigella dysenteriae type-1 vaccine in healthy volunteers: results of a Phase 2, randomized, double-blind placebo-controlled trial. Vaccine 27: 1184-1191.

74. Kotloff KL, Simon JK, Pasetti MF, Sztein MB, Wooden SL, et al. (2007) Safety and immunogenicity of CVD 1208S, a live, oral DeltaguaBA Deltasen Deltaset Shigella flexneri 2a vaccine grown on animal-free media. Hum Vaccin 3: 268-275.

75. Jiang ZD, Mathewson JJ, Ericsson CD, Svennerholm AM, Pulido C, et al. (2000) Characterization of enterotoxigenic Escherichia coli strains in patients with travelers' diarrhea acquired in Guadalajara, Mexico. J Infect Dis 181: 779-782.

76. Black RE (1993) Epidemiology of diarrhoeal disease: implications for control by vaccines. Vaccine 11: 100-106.

77. Abu-Elyazeed R, Wierzba TF, Mourad AS, Peruski LF, Kay BA, et al. (1999) Epidemiology of enterotoxigenic Escherichia coli diarrhea in a pediatric cohort in a periurban area of lower Egypt. J Infect Dis 179: 382-389.

78. Qadri F, Svennerholm AM, Faruque AS, Sack RB (2005) Enterotoxigenic Escherichia coli in developing countries: epidemiology, microbiology, clinical features, treatment, and prevention. Clin Microbiol Rev 18: 465-483.

79. Peltola H, Siitonen A, Kyrönseppä H, Simula I, Mattila L, et al. (1991) Prevention of travellers' diarrhoea by oral B-subunit/whole-cell cholera vaccine. Lancet 338: 1285-1289.

80. Boedeker EC (2005) Vaccines for enterotoxigenic Escherichia coli: current status. Curr Opin Gastroenterol 21: 15-19.

81. Wennerås C, Erling V (2004) Prevalence of enterotoxigenic Escherichia coli-associated diarrhoea and carrier state in the developing world. J Health Popul Nutr 22: 370-382.

82. Savarino S, Abu-Elyazeed R, Rao M, Frenck R, Abdel-Messih I, et al. (2003) Efficacy of an oral inactivated whole-cell enterotoxigenic E.coli/ choleratoxin B subunit vaccine in Egyptian infants. Proceedings of the 6th Annual Conference on Vaccine Research.

83. Wiedermann G, Kollaritsch H, Kundi M, Svennerholm AM, BjareU (2000) Double-blind, randomized, placebo controlled pilot study evaluating efficacy and reactogenicity of an oral ETEC B-subunitinactivated whole cell vaccine against travelers' diarrhea (preliminary report). J Travel Med 7: 27-29.

84. Güereña-Burgueño F, Hall ER, Taylor DN, Cassels FJ, Scott DA, et al. (2002) Safety and immunogenicity of a prototype enterotoxigenic Escherichia coli vaccine administered transcutaneously. Infect Immun 70: $1874-1880$

85. Tacket CO, Pasetti MF, Edelman R, Howard JA, Streatfield S (2004) Immunogenicity of recombinant LT-B delivered orally to humans in transgenic corn. Vaccine 22: 4385-4389.

86. Barry EM, Wang J, Wu T, Davis T, Levine MM (2006) Immunogenicity of multivalent Shigella-ETEC candidate vaccine strains in a guinea pig model. Vaccine 24: 3727-3734.

87. Khan S, Chatfield S, Stratford R, Bedwell J, Bentley M, et al. (2007) Ability of SPI2 mutant of S. Typhi to effectively induce antibody responses to the mucosal antigen enterotoxigenic E. coli heat labile toxin B subunit after oral delivery to humans. Vaccine 25: 4175-4182.

88. Daley A, Randall R, Darsley M, Choudhry N, Thomas N, et al. (2007) Genetically modified enterotoxigenic Escherichia coli vaccines induce mucosal immune responses without inflammation. Gut 56: 1550-1556.

89. Svennerholm AM, Lundgren A (2012) Recent progress toward an enterotoxigenic Escherichia coli vaccine. Expert Rev Vaccines 11: 495-507.

90. Holmgren J, Bourgeois L, Carlin N, Clements J, Gustafsson B, et al. (2013) Development and preclinical evaluation of safety and immunogenicity of an oral ETEC vaccine containing inactivated E. coli bacteria overexpressing colonization factors CFA/I, CS3, CS5 and CS6 combined with a hybrid LT/CT B subunit antigen, administered alone and together with dmLT adjuvant. Vaccine 31: 2457-2464.

91. Azizi A, Kumar A, Diaz-Mitoma F, Mestecky J (2010) Enhancing oral vaccine potency by targeting intestinal M cells. PLoS Pathog 6: e1001147. 